\title{
DIGITAL EVALUATION OF DIMENSIONAL ACCURACY AND INTIMACY OF FIT OF SINGLE- PIECE CLOSED HOLLOW BULB OBTURATORS FABRICATED BY CAD/CAM ADDITIVE MANUFACTURING
}

\author{
Akram F. Neena ${ }^{1 *} M S c$, Ahmed M. Alshimy ${ }^{2} P h D$, Mohamed M. Khamis ${ }^{3} P h D$, Amr M. \\ Ekram $^{4} P h D$
}

\begin{abstract}
INTRODUCTION: Conventional techniques for closed hollow bulb obturators construction are technique sensitive, consume considerable amount of materials, and lack adequate control of the walls thickness of the bulb. Additionally, created sealing area is a potential site of leakage and discoloration. Digital technologies offer promising solutions to these drawbacks. Subtractive manufacturing systems are unable to produce hollow objects as one piece. In contrast, additive manufacturing systems can produce a hollow object in one piece.

OBJECTIVES: The aim of the present study was to evaluate one-piece closed hollow bulb obturators fabricated using CAD/CAM additive manufacturing and compare them to those constructed from heat cured resin.

MATERIALS AND METHODS: Six partially dentate patients with healed unilateral maxillary defects (Aramany's classes I or II) received two closed hollow bulb obturators. One constructed using CAD/CAM additive manufacturing, and another constructed from conventional acrylic resin. All patients' prostheses were evaluated for dimensional accuracy and intimacy of fit using digital measuring software package. RESULTS: CAD/CAM obturators showed negative dimensional change values when compared to the original design, while Heat-cured obturators showed positive ones. Generally, the highest values of deviations were recorded at occlusal units for CAD/CAM obturators (-0.34 $\pm 0.10)$ and Heat-cured obturators $(0.21 \pm 0.12)$ when fitting surface was used as reference. There were statistical significant differences in dimensional deviation between both obturator groups using two registration references. CAD/CAM obturators showed lower misfit values when compared to Heat-cured ones. The highest values of misfit were recorded at the oral extensions of the CAD/CAM (0.44 \pm 0.27$)$ and Heat-cured obturators $(0.47 \pm 0.32)$. However, there were no statistical significant differences between both obturator groups at any measured surface.

CONCLUSIONS: Additive manufacturing of obturators could be an alternative to conventional techniques for direct construction of onepiece closed hollow bulb obturators.

KEYWORDS: Digital dimensional accuracy, intimacy of fit, additive manufacturing, closed hollow bulb, single-piece obturators.
\end{abstract}

1- Assistant lecturer of Removable Prosthodontics, Faculty of Dentistry, Alexandria University

2- Professor and Head of Removable Prosthodontics Department, Faculty of Dentistry, Alexandria University

3- Professor of Removable Prosthodontics, Faculty of Dentistry, Alexandria University

4- Oral and Maxillofacial Surgery consultant, Faculty of Dentistry, Cairo University

* Corresponding author:

E-mail: loxinternational2000@yahoo.com

\section{INTRODUCTION}

Acquired maxillary defects could be due to tumors, pathological changes, trauma, radiation, burns, or surgical intervention. The size of these defects can vary from small to extremely large resections, and sometimes they may extend to extraoral structures. Such defects usually result in oroantral communication that causes hypernasal speech, fluid leakage into the nasal cavity, impaired masticatory function, difficulty in swallowing, temporomandibular joint problems, and facial disfigurement (1).

In patients where surgical reconstruction is not the best treatment option, prosthodontist plays an important role in the rehabilitation of their defects with obturator prostheses to recreate separation between oral and nasal cavities. These prostheses vary in size and shape that directly affect their retention, stability, and support (2).

Various hard and soft materials have been used to construct obturator prostheses. Heat-cured acrylic resin, up to the present moment, is still considered one of the most durable and biocompatible materials for obturator construction (1).

In recent years, a limited number of biocompatible photopolymer resins have been developed and applied in additive manufacturing (AM). These photoresins were declared for being biocompatible (3), but these recently declared photoresins still require further research to confirm their clinical applicable biocompatibility.

Since the weight of an obturator is often the most common reason for dislodgment, it should be made light in weight by hollowing out of the bulb portion (4). The available literature described various methods for fabricating open and closed hollow bulb obturator prostheses. Open hollow bulb obturators often collect mucous, food, and fluids and need numerous cleanings (5). Closed hollow bulb obturators, on the other hand, do not pool moisture, while still extending adequately into the defect (6).

Conventional methods for closed hollow bulb obturator construction are generally technique sensitive, consume 
considerable amount of materials, share a limited access to the inner aspects of the bulb, and usually create sealing area which is a potential site of leakage and discoloration $(7,8)$.

Elshimy (9) suggested a technique for fabrication of closed hollow bulb obturators that include sequential building up of the prosthesis in sections made up of heatcured acrylic resin. The technique starts by building the nasal extension of the obturator first. Then a covering lid is constructed over it to ensure keeping it hollow while the final processing step. The nasal part and its lid are then incorporated in the master cast on which teeth are arranged for final processing of the palatal extension of the obturator. By this technique, all exposed surfaces of the obturator are made of heat-cured acrylic resin and the sealing area is buried within the obturator body.

Digital technologies offer promising solutions to the drawbacks encountered with conventional methods. Using Computer Aided Designing/Computer Aided Manufacturing (CAD/CAM), design of the prosthesis with the desired wall thickness and configuration can be achieved by the CAD software first, and then the prosthesis can be manufactured. AM systems are able to produce onepiece closed hollow objects, which make them more suitable to application in obturator construction if compared to subtractive manufacturing systems.

It was suggested that using 3D printed patient's skull model based on post-surgical Computerized Tomography (CT) scans of the patient's face can allow surgeons to design an obturator that fits exactly in the 3D printed replica (10). On the same line, Michelinakis (11) used a Cone Beam Computerized Tomography (CBCT) of the maxilla to construct a 3D resin model on which an obturator was made out of wax and was fitted with teeth, which was then converted to acrylic resin using conventional flasking procedures. He proposed that the method presented can limit the impression stages needed for construction of maxillary obturator prosthesis to a single impression procedure. This can be very beneficial to the patient suffering from postradiation side effects such as trismus, mucositis, and xerostomia.

Elbashti et al (12) extended the idea of using CAD/CAM from construction process to ability of the technology to create a digitized database of fabricated acrylic obturators to be kept for patients' potential emergency needs. Their results showed that the obturator can be successfully scanned regardless of its structural complexity, modeled as three-dimensional data, and stored in the digital system. To verify accuracy of production, they conducted computerized analysis of re-produced obturators to original ones and found insignificant dimensional deviations.

Tasopoulos et al (13) reported construction of twopiece definitive obturator for completely edentulous patient using 3D printing of the remarkably large palatal defect using a CT scan data. The printed model was used for making a wax pattern for the extensive nasal part without the need for making an impression to the defected site. The pattern was then placed in the patient's mouth for a pick up impression procedure that was used to pour a master cast on which the following steps were completed in conventional manner.

Ye et al (14) tried to generate 3D digital casts of maxillary defects, including the defective region and the maxillary dentition, based on multisource data registration and evaluated their clinical effectiveness. The maxillofacial region was scanned $\mathrm{CT}$, and the maxillary arch and palate were scanned using an intraoral optical scanner. The 3D images from the CT and intraoral scanner were registered and merged to form a 3D digital cast of the maxillary defect containing the anatomic structures needed for the maxillary prosthesis. They concluded that these digital casts were consistent with conventional stone casts in terms of accuracy and were suitable for clinical use.

In the past few years, control of geometry in industry is carried out using devices that apply computerized coordinate measuring technique. This computerized technique is of the latest evolutions in dentistry which in turn makes it open for many possible applications in researches regarding aspects of accuracy (15).

According to van Eijnatten et al (16), optical scanning for data acquisition is considered the "gold standard" for accuracy assessment. They suggested that to quantify the accuracy of AM process, the Standard Tessellation Language (STL) model obtained from an optical scanner of the first model should be additively manufactured and then optically scanned and compared with the original STL model.

Regardless of the method used to scan the object, the measurement results should be converted into mesh of triangles or STL file. After that, the analysis can be conducted in different measuring software packages such as the GOM Inspect freeware which was applied in many investigations (12,15-19).

Digital methods emerging in the past decade has various applications regarding aspects of accuracy. They even can be extended beyond geometrical accuracy comparison to help finding intimacy of fit between various objects (15).

Chen et al (20) suggested a digital technique to quantitatively evaluate the tissue surface adaption of a maxillary complete denture wax pattern produced by CAD/CAM. The cast model and the two wax patterns to be evaluated for tissue adaption were separately scanned. Then after setting each wax pattern on the plaster cast, the whole model was re-scanned for registration. After registration, the deviations of tissue surface between the wax patterns and the cast model were measured. They concluded that this procedure is an objective method to quantify surface adaption between objects.

It is important to mention that there is very limited data on the accuracy of 3D printed resins used with long-term dental applications as denture bases. It is very likely that significant quality improvement will occur in the future making this technology very competitive with the existing fabrication methods (21).

There are few published trials reported using the CAD/CAM AM in the indirect construction of maxillary obturators. While there is no published literature using $\mathrm{CAD} / \mathrm{CAM} \mathrm{AM}$ in the direct construction of closed hollow bulb obturators.

Thus, this research aimed to introduce and evaluate a new technique using CAD/CAM AM in the direct construction of one-piece closed hollow bulb obturators and compare them to conventional heat-cured acrylic resin obturators for patients with acquired maxillary defects.

The null hypothesis of this study is that the CAD/CAM AM of obturators will not show any significant improvement on digital evaluation aspects of dimensional 
changes and tissue misfit when compared to the conventional ones.

\section{MATERIALS AND METHODS}

To carry out this study, a sample of six patients was selected from those diagnosed at the maxillofacial prosthetic unit at the Prosthodontic Department, Faculty of Dentistry, Alexandria University.

All patients were partially dentate with a unilateral maxillary surgical defect (Aramany’s classes I and II) (22) that was indicated for construction of hollow bulb obturator. The surgical defect has healed with at least six months elapsed from the completion of the surgical and/or adjunctive treatment. Patients' age range was 25 to 60 years with mean of 43.83 .

Written informed consents were obtained from all patients who accepted to share in this study after the procedures were explained to them. All patients received appropriate dental care including removal of local factors, education and motivation to maintain proper oral hygiene.

For each patient in this study, two obturators were fabricated; a conventional heat-cured acrylic resin [Vertex rapid simplified, Vertex Dental B.V., The Netherlands] obturator following Elshimy's modifications to conventional technique (9), and a closed hollow bulb acrylic obturator fabricated using CAD/CAM AM system.

\section{CAD/CAM prosthesis construction (23)}

Preliminary impressions with irreversible hydrocolloid impression material were made on a modified stock tray. The maxillary final impression was made on customized tray using elastomeric impression material. The final impression was boxed and then poured in artificial stone to obtain the master cast. On the master cast, all undesirable undercuts were obliterated with pure stone and relief of sensitive areas was carried out as usual. The modified master cast was then duplicated. Record blocks were constructed and extended into the surgical part to assure stability when the maxillo-mandibular relationships were recorded. The relations were then transferred to an articulator on which artificial teeth [New Ace \& Naperce. Yamahachi Dental, Japan] were arranged. Trial of the waxed-up obturator was then made intraorally to assess esthetics, occlusion, and facial support.

After the try-in, the laboratory optical scanner [SmartOptics activity 855, Smartoptics Sensortechnik GmbH. Germany] was used to obtain three virtual models through scanning: the modified master cast alone, the master cast with the waxed-up prosthesis on it, and the master cast with the prosthesis with no teeth on it.

The 3D CAD software [PlastyCAD, 3DIEMME. Italy. Autodesk Meshmixer, Autodesk Inc. USA] was then used for the following: 1) All virtual models were imported for registration using the multipoint alignment and best fit alignment commands. 2) Each two models were subtracted to obtain two separate virtual replicas of the waxed-up obturator base and the teeth on the software (Figure 1a). 3) The bulb portion of the virtual obturator base was then hollowed leaving a $2 \mathrm{~mm}$ wall thickness all around (Figure 1b). 4) Two venting holes of $1 \mathrm{~mm}$ diameter were designed and placed on the virtual obturator base; one at an anterior tooth socket and another at a posterior one, to allow washing the inner aspects of the bulb cavity with alcohol later on.

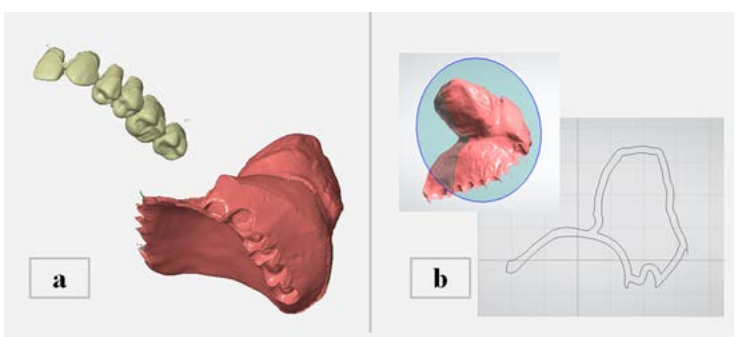

Figure (1): Showing 3D CAD software used for designing of CAD/CAM obturators. a) Original models were subtracted to obtain two separate virtual replicas of the waxed-up obturator base and the teeth on the software. b) Bulb portion of the virtual obturator base was hollowed leaving a $2 \mathrm{~mm}$ wall thickness all around.

The 3D printing machine [Planmeca Creo, Planmeca. Finland] was then used to produce two separate 3D prints: a print of the obturator base in printable pink colored resin material [NextDent Base. NextDent. The Netherlands], and a print of the teeth in printable tooth-colored resin material [NextDent C\&B. NextDent. The Netherlands].

The supports of the 3D prints were mechanically removed and the two prints were finished. The outer surfaces of the finished teeth and obturator base prints and the inner bulb cavity were then washed using $90 \%$ alcohol solution to remove excess uncured resin. The finished obturator base was then seated over the duplicate master cast after cutting off the defect part. Retentive boxes were cut into the polished surface of the obturator base creating space for the required wrought wire claps needed for retention. The created space was then filled with a thin film of uncured pink colored resin material to cover the retentive tags of the clasps while in place. The uncured resin was then cured using ultraviolet light-emitting-diode (UV LED) flashlight pen for 30 seconds.

The venting holes were then sealed by applying a drop of uncured pink colored resin then curing it using UV LED flashlight pen for 30 seconds. The two prints of the obturator base and teeth were then assembled together with a thin film of uncured pink colored resin material that was then cured using UV LED flashlight pen for 30 seconds. The assembled obturator was then placed in the UV postcuring machine [Otoflash post curing light pulsing unit, EnvisionTEC Inc. USA] for final curing. The completed obturator was then polished to be ready for delivery.

At time of each obturator delivery, obturator base was relieved till the obturator seated without pressure and artificial teeth were adjusted to eliminate interferences and achieve comfort with the obturator. All patients were provided by same instructions and tools for wearing, cleaning and how to use their obturators.

\section{Digital evaluation for obturator dimensional accuracy $(12,17)$}

For each fabricated obturator in this study, the laboratory optical scanner was used twice to capture the geometries of polished and fitting surfaces of the fabricated obturator; generating two separate 3D scans. The two scans were then imported in the CAD software for registration using the multipoint alignment and best fit alignment commands, then the two scans were combined to formulate a digital replica of the fabricated obturator. 
Virtual models of CAD/CAM and heat-cured acrylic obturators at time of delivery were imported to the CAD software for registration to the 3D model of the waxed-up obturator base and teeth formulated before 3D printing. Two references for registration were used in this study; the first used the obturator fitting surface, and the second used the overall obturator surface for registration. Geometries of both fabricated obturators were then compared to those of the 3D obturator pre-printing model using the measuring software package [GOM Inspect Software 2016. GOM $\mathrm{GmbH}$, Germany] to obtain color maps of dimensional deviations (Figure 2). Mean values of dimensional deviations of the overall as well as specified surfaces on the obturator were then calculated and were used for statistical analysis.
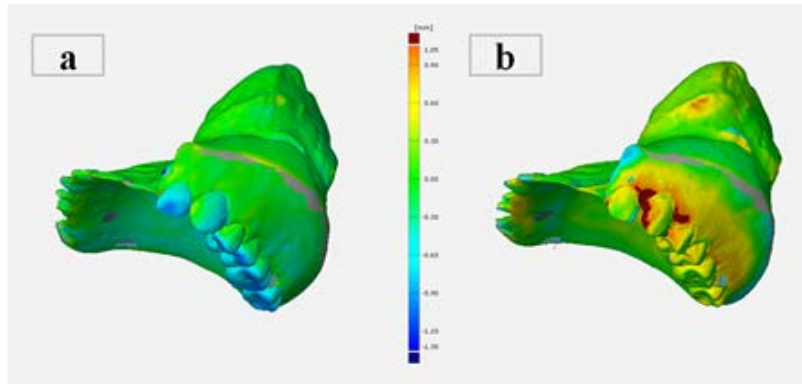

Figure (2): Showing color maps of dimensional deviation. a) CAD/CAM obturator dimensional deviation. b) Heat-cured obturator dimensional deviation.

\section{Digital evaluation for obturator-tissue relation $(20,24)$}

Multiple glass beads as radiographic markers were scattered and attached to the polished surfaces of the two obturators fabricated for each patient. Using CBCT machine [Morita, Veraviewepocs 3D R100. USA], three radiographic scans were made to capture the geometries of patient's mouth; once with no obturator, once with CAD/CAM obturator, and once with Heat-cured one. Each patient was instructed to close gently on two cotton rolls placed bilaterally between jaws during each CBCT scan made. All obtained Digital Imaging and Communications in Medicine (DICOM) data were converted to virtual 3D STL models. The two obturators with attached glass beads were also scanned using the optical laboratory scanner to formulate digital replicas of the obturators.

All the virtual models were then imported to the CAD software. All 3D models obtained from the CBCT were then registered to each other using multipoint alignment and best fit alignment commands. The glass beads surfaces were then used to register the two digital replicas of both obturators to their corresponding CBCT models (Figure 3). The patient's master cast 3D scan was then imported to the CAD software, and was registered to the CBCT model of the patient's mouth with no obturators using the natural teeth surfaces for registration.

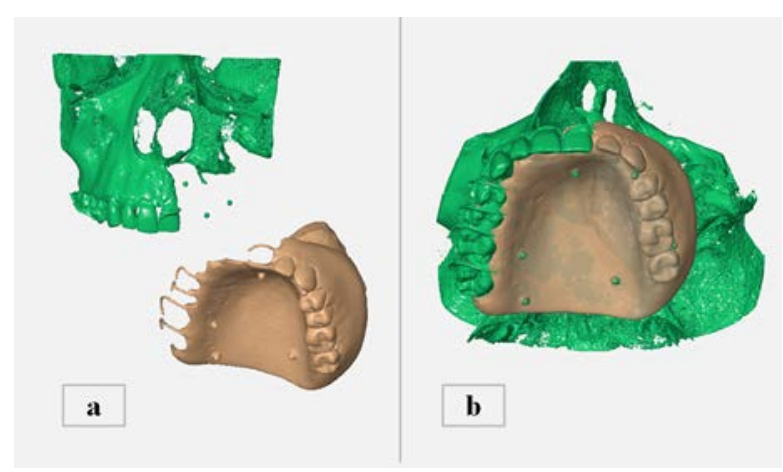

Figure (3): Showing registration process of an obturator to its clinical position to aid calculating obturator-tissue misfit. a) STL models ready for registration; CAD/CAM obturator with attached glass beads, and patient's CBCT wearing that obturator, b) The glass beads were used for registration of the obturator to its accurate clinical position.

After registration, color maps of gap distance between the fitting surface of each type of the two obturators and the patient's master cast were formulated using the measuring software package (Figure 4). Mean values of gap distance of the overall as well as specified surfaces on the obturator were then calculated and used for statistical analysis.

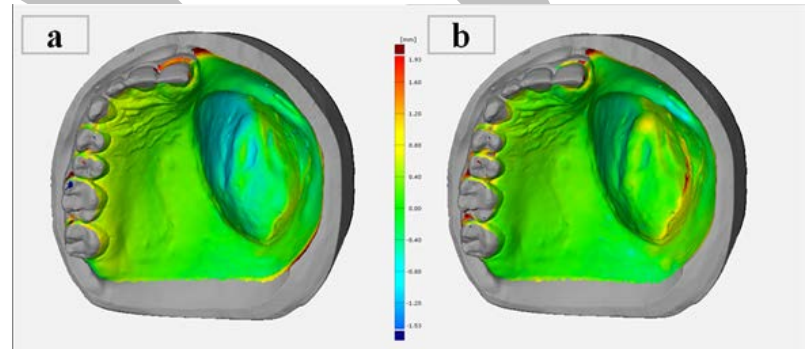

Figure (4): Showing color maps of the obturator-tissue relation. a) $\mathrm{CAD} / \mathrm{CAM}$ obturator misfit. b) Heat-cured obturator misfit.

\section{Statistical analysis $(25,26)$}

Data were fed to the computer and analyzed using IBM SPSS software package version 20.0. Quantitative data were described using Range (minimum and maximum), mean, standard deviation and median. Data analysis of mean values of dimensional deviations and obturators misfit were done by Wilcoxon signed ranks and Mann Whitney test. Significance of the obtained results was judged at the $5 \%$ level. A p-value of less than 0.05 was considered statistically significant.

\section{RESULTS}

\section{Dimensional deviations of the two obturator groups}

Table 1 shows the range (minimum and maximum), median, mean, and standard deviation values of volumetric dimensional deviations measured in mm for both types of obturators. Figure 5a shows the mean values of dimensional deviations of both types of obturators under study. Figure 5b shows a box-plot of the median and range values of dimensional deviations of both types of obturators under study. 


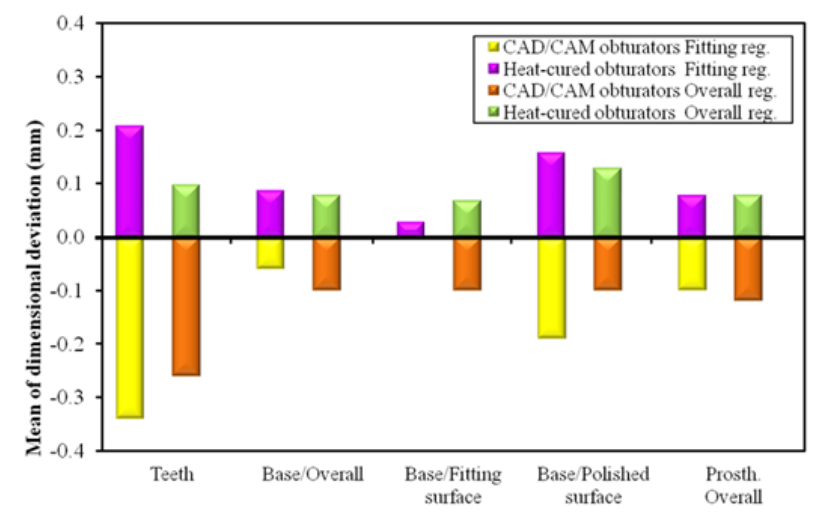

Figure (5a): Showing the mean values of dimensional deviations of both types of obturators under study. Measurements are presented in $\mathrm{mm}$.

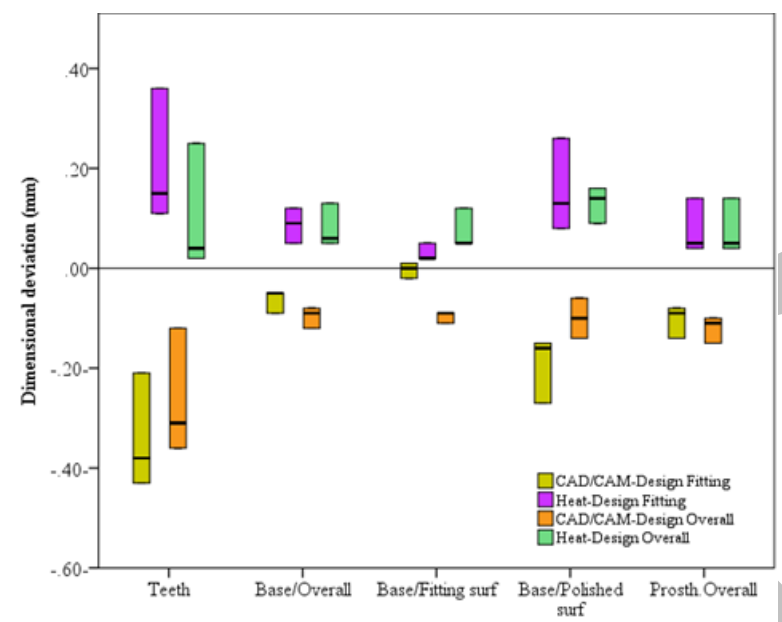

Figure (5b): Showing the median and range values of dimensional deviations of both types of obturators under study. Measurements are presented in $\mathrm{mm}$.

Table (1): Showing comparison between volumetric dimensional accuracy of CAD/CAM and Heat-cured acrylic obturators. Measurements are presented in $\mathrm{mm}$.

\begin{tabular}{|c|c|c|c|c|c|}
\hline & Surface studied & & 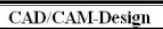 & $\overline{\text { Heat-Design }}$ & $\mathrm{p1}$ \\
\hline \multirow{5}{*}{ 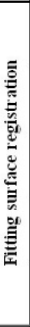 } & $\begin{array}{l}\text { Teeth occlusal } \\
\text { units }\end{array}$ & $\begin{array}{l}\text { Min. - Max. } \\
\text { Mean } \pm \text { SD. } \\
\text { Median }\end{array}$ & $\begin{array}{c}-0.43--0.21 \\
-0.34 \pm 0.10 \\
-0.38\end{array}$ & $\begin{array}{c}0.11-0.36 \\
0.21 \pm 0.12 \\
0.15\end{array}$ & $0.026^{\circ}$ \\
\hline & Base/Overall & $\begin{array}{l}\text { Min. }- \text { Max. } \\
\text { Mean } \pm \text { SD. } \\
\text { Median }\end{array}$ & $\begin{array}{c}-0.09--0.05 \\
-0.06 \pm 0.02 \\
-0.05\end{array}$ & $\begin{array}{c}0.05-0.12 \\
0.09 \pm 0.03 \\
0.09\end{array}$ & $0.026^{\circ}$ \\
\hline & $\begin{array}{l}\text { Base/ Fitting } \\
\text { surface }\end{array}$ & $\begin{array}{l}\text { Min. - Max. } \\
\text { Mean } \pm \text { SD. } \\
\text { Median }\end{array}$ & $\begin{array}{c}-0.02-0.01 \\
0.0 \pm 0.01 \\
0.0\end{array}$ & $\begin{array}{c}0.02-0.05 \\
0.03 \pm 0.02 \\
0.02\end{array}$ & $0.026^{\circ}$ \\
\hline & $\begin{array}{l}\text { Base/Polished } \\
\text { surface }\end{array}$ & $\begin{array}{l}\text { Min. }- \text { Max. } \\
\text { Mean } \pm \text { SD. } \\
\text { Median }\end{array}$ & $\begin{array}{c}-0.27--0.15 \\
-0.19 \pm 0.06 \\
-0.16\end{array}$ & $\begin{array}{c}0.08-0.26 \\
0.16 \pm 0.08 \\
0.13\end{array}$ & $0.026^{\circ}$ \\
\hline & Prosth.Overall & $\begin{array}{l}\text { Min. }- \text { Max. } \\
\text { Mean } \pm \text { SD. } \\
\text { Median }\end{array}$ & $\begin{array}{c}-0.14--0.08 \\
-0.10 \pm 0.03 \\
-0.09\end{array}$ & $\begin{array}{c}0.04-0.14 \\
0.08 \pm 0.05 \\
0.05\end{array}$ & $0.023^{\circ}$ \\
\hline \multirow{11}{*}{ 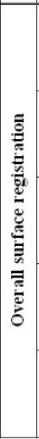 } & $\begin{array}{l}\text { Teeth occlusal } \\
\text { units }\end{array}$ & $\begin{array}{c}\text { Min. }- \text { Max. } \\
\text { Mean } \pm \text { SD. } \\
\text { Median }\end{array}$ & $\begin{array}{c}-0.36--0.12 \\
-0.26 \pm 0.11 \\
-0.31\end{array}$ & $\begin{array}{c}0.02-0.25 \\
0.10 \pm 0.11 \\
0.04\end{array}$ & \multirow[t]{2}{*}{$0.026^{\circ}$} \\
\hline & & $\mathrm{p}^{2}$ & $0.023^{*}$ & $0.023^{\circ}$ & \\
\hline & \multirow[t]{2}{*}{ Base/ Overall } & $\begin{array}{l}\text { Min. }- \text { Max. } \\
\text { Mean } \pm \text { SD. } \\
\text { Median }\end{array}$ & $\begin{array}{c}-0.12--0.08 \\
-0.10 \pm 0.02 \\
-0.09\end{array}$ & $\begin{array}{c}0.05-0.13 \\
0.08 \pm 0.04 \\
0.06\end{array}$ & \multirow[t]{2}{*}{$0.026^{\circ}$} \\
\hline & & p2 & $0.023^{*}$ & 0.458 & \\
\hline & \multirow[t]{2}{*}{$\begin{array}{l}\text { Base/ Fitting } \\
\text { surface }\end{array}$} & $\begin{array}{l}\text { Min. }- \text { Max. } \\
\text { Mean } \pm \text { SD. } \\
\text { Median }\end{array}$ & $\begin{array}{c}-0.11--0.09 \\
-0.10 \pm 0.01 \\
-0.09\end{array}$ & $\begin{array}{c}0.05-0.12 \\
0.07 \pm 0.04 \\
0.05\end{array}$ & \multirow[t]{2}{*}{$0.023^{\circ}$} \\
\hline & & $\mathrm{p} 2$ & $0.023^{*}$ & $0.023^{\circ}$ & \\
\hline & \multirow{2}{*}{$\begin{array}{l}\text { Base/Polished } \\
\text { surface }\end{array}$} & $\begin{array}{l}\text { Min. }- \text { Max. } \\
\text { Mean } \pm \text { SD. }\end{array}$ & $\begin{array}{l}-0.14--0.06 \\
-0.10 \pm 0.04\end{array}$ & $\begin{array}{l}0.09-0.16 \\
0.13 \pm 0.03\end{array}$ & \multirow{2}{*}{0.026} \\
\hline & & $\frac{\text { Median }}{p^{2}}$ & $\begin{array}{c}-0.10 \\
0.026^{*}\end{array}$ & $\begin{array}{l}0.14 \\
0.459\end{array}$ & \\
\hline & \multirow{3}{*}{ Prosth. Overall } & Min.-Max. & $-0.15--0.10$ & $0.04-0.14$ & \multirow{3}{*}{$0.023^{\circ}$} \\
\hline & & $\begin{array}{l}\text { Mean } \pm \mathrm{SD} \\
\text { Median }\end{array}$ & $\begin{array}{c}-0.12 \pm 0.02 \\
-0.11\end{array}$ & $\begin{array}{l}0.08 \pm 0.05 \\
0.05\end{array}$ & \\
\hline & & $\mathrm{p} 2$ & $0.023^{*}$ & 1.000 & \\
\hline
\end{tabular}

p1: $p$ value of Wilcoxon signed ranks test for comparing between CAD/CAM to Design and Heat-ceured to Design.

p2: $p$ value of Wilcoxon signed ranks test for comparing between fitting and overall registration values.

*: Statistically significant at $\mathrm{p} \leq 0.05$
The CAD/CAM obturators showed negative deviation values denoting that produced obturators were of more extended dimensions when compared to the original design. On the other hand, The Heat-cured obturators showed positive deviation values denoting that produced obturators were of smaller dimensions when compared to the original design.

For CAD/CAM obturators, highest values of deviations were recorded at occlusal units when fitting and overall registration references were used, $(-0.34 \pm 0.10)$ and $(-0.26$ \pm 0.11 ) consequently. For Heat-cured obturators, highest values were recorded at occlusal units $(0.21 \pm 0.12)$ when fitting surface was used as reference. When the overall surface of obturator was used as reference in Heat-cured obturators, the highest values were recorded on the polished surface of the obturator base $(0.13 \pm 0.03)$.

There were statistical significant differences between all dimensional deviations values measured at any part of the prosthesis of both obturators when compared to each other using both registration references. When both registration references were compared within each obturator group, statistical significant differences were found except for the heat-cured occlusal units, Heat-cured polished surfaces, and Heat-cured overall prosthesis surfaces.

\section{Results of misfit of the two obturator groups}

Table 2 shows the range (minimum and maximum), mean and standard deviation values of tissue misfit measured in $\mathrm{mm}$ for both types of obturators. Figure 6 presents the mean values of tissue misfit of both types of obturators under study.

CAD/CAM obturators showed lower overall misfit values $(0.28 \pm 0.18)$ when compared to Heat-cured ones $(0.45 \pm 0.21)$. The highest values of misfit of both groups were recorded at the oral extensions of the CAD/CAM and Heat-cured obturators, $(0.44 \pm 0.27)$ and $(0.47 \pm 0.32)$ consequently. However, there were no statistical significant differences between both obturator groups at any measured surface.

Table (2): Showing comparison between intimacy of fit of CAD/CAM and Heat-cured acrylic obturators. Measurements are presented in $\mathrm{mm}$.

\begin{tabular}{||c|c|c|c||}
\hline Misfit (mm) & $\begin{array}{c}\text { CAD/CAM } \\
(\mathbf{n}=\mathbf{6})\end{array}$ & $\begin{array}{c}\text { Heat-cured } \\
(\mathbf{n = 6})\end{array}$ & $\mathbf{p}$ \\
\hline \begin{tabular}{|} 
Oral surface extension \\
Min. - Max.
\end{tabular} & $0.20-0.78$ & $0.19-0.87$ & 0.746 \\
Mean \pm SD. & $0.44 \pm 0.27$ & $0.47 \pm 0.32$ & \\
\hline $\begin{array}{c}\text { Nasal surface extension } \\
\text { Min. - Max. }\end{array}$ & $0.02-0.28$ & $0.18-0.66$ & 0.106 \\
Mean \pm SD. & $0.18 \pm 0.12$ & $0.44 \pm 0.22$ & \\
\hline $\begin{array}{c}\text { Overall surface } \\
\text { Min. - Max. }\end{array}$ & $0.07-0.46$ & $0.18-0.62$ & 0.106 \\
Mean \pm SD. & $0.28 \pm 0.18$ & $0.45 \pm 0.21$ & \\
\hline
\end{tabular}

p: p value of Mann Whitney test for comparing between the two groups

*: Statistically significant at $\mathrm{p} \leq 0.05$ 


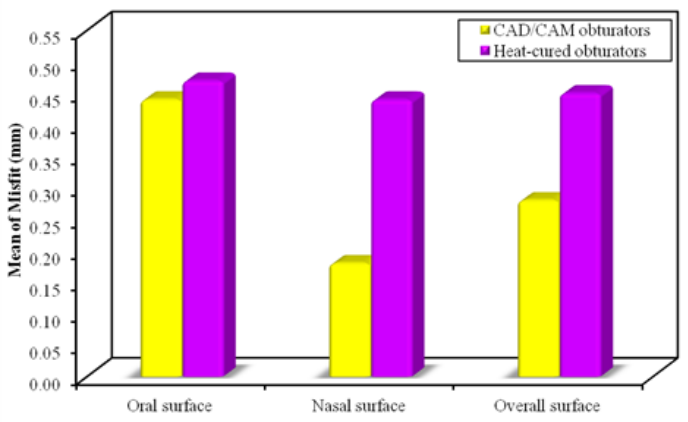

Figure (6): Showing the mean values of tissue misfit of both types of obturators. Measurements are presented in $\mathrm{mm}$.

\section{DISCUSSION}

\section{Analysis of resulting dimensional deviations of the two groups}

The digital process of producing prostheses involves various steps, each of which can be a source of dimensional error. Errors can occur during the imaging, segmentation or manufacturing phase. According to Salmi et al (18), different manufacturing methods may cause significant accuracy errors.

The CAD/CAM obturators constructed in this study showed negative deviation values denoting that produced obturators were of more extended dimensions when compared to the original design. The mean value of overall dimensional deviations of CAD/CAM obturators is $-0.10 \pm$ 0.03 . This finding is in line with the finding of Goodacre et al (27) who measured the overall dimensional deviation of fluid-resin dentures to be $(-0.09 \pm 0.154)$. For CAD/CAM obturators, occlusal units are most likely for occlusal interferences when delivered clinically. This could be assumed from the dimensional findings observed for this obturator group who had highest values of deviations at occlusal units when fitting and overall registration references were used, $(-0.34 \pm 0.10)$ and $(-0.26 \pm 0.11)$ consequently. However, dimensional accuracy of CAD/CAM AM would require further research on material properties and its manufacturing technique to obtain lower dimensional deviations. Based on similar findings, Salmi et al (18) recommended that clinicians using AM in prosthesis fabrication should be aware of these errors that originate from the technology used, material and instance of machine use

As the PMMA acrylic dough is pressed against the actual sized master cast during flasking, the final prosthesis is expected to show an overall reduction in dimensions as polymerization reaction of PMMA results in shrinkage after processing the prosthesis. The results of the Heat-cured obturators studied in this research were in line with this assumption. The Heat-cured obturators constructed in this research had overall positive deviation values $(0.08 \pm 0.05)$ denoting that produced obturators were of smaller dimensions when compared to the original design (28).

Polymerization shrinkage of conventional PMMA has two main effects. The shrinkage distorts the palate of a maxillary denture resulting in an inaccurate fit to the supporting tissues, and it affects the position of the teeth on maxillary and mandibular dentures, and thus the final occlusion of the dentures $(28,29)$ These two effects of polymerization shrinkage were evident in this study. For Heat-cured obturators, highest values were recorded at occlusal units $(0.21 \pm 0.12)$ when fitting surface was used as reference. When the registration reference was changed to overall surface of obturator, the highest values were recorded on the polished surface of the obturator base ( 0.13 $\pm 0.03)$.

When both registration references were compared within Heat-cured obturator group, no statistical significant differences were found for the heat-cured occlusal units, Heat-cured polished surfaces, and Heat-cured overall prosthesis surfaces. This varying results due to change in reference for registration supports the recommendation of Salmi et al (18) that a standard method should be developed for measuring and verifying prosthesis accuracy fabricated by AM. Further studies showed that imaging and segmentation together can cause even bigger errors than the manufacturing process itself $(16,30,31)$.

\section{Analysis of resulting miss fit of the two groups}

As the overall CAD/CAM obturators tend to have more extended dimensions, while the Heat-cured ones tend to show smaller ones, it seemed logical to have statistical significant differences between both groups when obturator-tissue relation was studied. However, this assumption was clinically not true. Although CAD/CAM obturators showed lower misfit values $(0.28 \pm 0.18)$ when compared to Heat-cured ones $(0.45 \pm 0.21)$, there were no statistical significant differences between both obturator groups at any measured surface. These findings are in line with those of Chen et al (20) who found higher adaption values for CAD/CAM bases.

The highest values of misfit of both groups were recorded at the oral extensions of the CAD/CAM and Heatcured obturators, $(0.44 \pm 0.27)$ and $(0.47 \pm 0.32)$ consequently. For the CAD/CAM group, it seems that the overall increase in dimensions of the produced prosthesis shifts the palatal extension of the obturator away from the tissues. This seems logical as the mean misfit value of the nasal extension of those prostheses was $(0.18 \pm 0.12)$. For the Heat-cured group, misfit could be attributed to distortion occurring at the cross-arch region as stated by Parvizi et al (28) that "the greatest distortion occurs in the cross-arch region when the denture is deflasked. This has been attributed to the release of internal stresses developed during processing, and the difference in the coefficient of thermal expansion between stone cast and acrylic resin".

\section{CONCLUSION}

The CAD/CAM obturators constructed by AM have tendency to have more extended dimensions when compared to the original design. This would require further research on material properties and its manufacturing technique to obtain lower dimensional deviations. For CAD/CAM obturators, occlusal units are most likely for occlusal interferences when delivered clinically. This could be assumed from the dimensional findings observed for this obturator group. Accurate and solid reference for virtual models registration is of great importance especially when $\mathrm{CAD} / \mathrm{CAM}$ accuracy is on the scale, as this could affect the obtained results. CAD/CAM obturators showed closer relation to oral tissues when compared to Heat-cured ones. Based on these findings, CAD/CAM AM of obturators could be an alternative processing technique to conventional ones used for direct construction of one-piece closed hollow bulb obturators. However, this assumption should be further investigated. 


\section{ACKNOWLEDGMENT}

I would like to thank my dear professors and colleagues for their continuous support during conduction of this study.

\section{CONFLICT OF INTEREST}

The authors declare that they have no conflicts of interest.

\section{REFERENCES}

1-Beumer J, Curtis TA, Marunick MT, editors. Maxillofacial rehabilitation: prosthodontic and surgical considerations, 1st ed. Ishiyaku Euroamerica; 1996.

2-Shinde B, Jadhav GR, Mittal P. Hollow Bulb Obturator Prosthesis Following Palatal Resection: A Case Report. Glob J Oral Sci. 2016;2:6-9.

3-Voet VS, Strating T, Schnelting GH, Dijkstra P, Tietema M, $\mathrm{Xu}$ J, et al. Biobased Acrylate Photocurable Resin Formulation for Stereolithography 3D Printing. ACS Omega. 2018;3:1403-8.

4-Oh W, Roumanas ED. Optimization of maxillary obturator thickness using a double-processing technique. J Prosthodont. 2008;17:60-3

5-McAndrew KS, Rothenberger S, Minsley GE: An innovative investment method for the fabrication of a closed hollow obturator prosthesis. J Prosthet Dent 1998;80:12932

6-Phankosol P, Martin JW. Hollow obturator with removable lid. J Prosthet Dent 1985;54:98-100

7-Schwartzman B, Caputo AA, Beumer J. Gravity-induced stresses by an obturator prosthesis. J Prosthet Dent 1990;64:466-8

8-Minsley GE, Nelson DR, Rothenberger SL. An alternative method for fabrication of a closed hollow obturator. J Prosthet Dent 1986;55:466-8

9-Elshimy AM. Speech evaluation for resected maxilla after insertion of the palatal obturator with various nasal extensions. Doctor Degree thesis. Alexandria University. 1988

10-Bauermeister AJ, Zuriarrain A, Newman MI. Threedimensional printing in plastic and reconstructive surgery: a systematic review. Ann Plast Surg. 2016;77:569-76.

11-Michelinakis G. The use of cone beam computed tomography and three dimensional printing technology in the restoration of a maxillectomy patient using a dental implant retained obturator. J Indian Prosthodont Soc. 2017; 17:406

12-Elbashti M, Hattori M, Sumita Y, Aswehlee A, Yoshi S, Taniguchi H. Creating a digitized database of maxillofacial prostheses (obturators): A pilot study. J Adv Prosthodont. 2016;8:219-23

13-Tasopoulos T, Kouveliotis G, Polyzois G, Karathanasi V. Fabrication of a 3D printing definitive obturator prosthesis: A Clinical report. Acta Stomatol Croat. 2017;51:53-9

14-Ye H, Ma Q, Hou Y, Li M, Zhou Y. Generation and evaluation of 3D digital casts of maxillary defects based on multisource data registration: A pilot clinical study. J Prosthet Dent. 2017;118:790-5

15-Gapinski B, Wieczorowski M, Marciniak-Podsadna L, Dybala B, Ziolkowski G. Comparison of different method of measurement geometry using CMM, optical scanner and computed tomography 3D. Procedia Eng. 2014;69:255-62

16-van Eijnatten M, Rijkhorst EJ, Hofman M, Forouzanfar T, Wolff J. The accuracy of ultrashort echo time MRI sequences for medical additive manufacturing. Dentomaxillofac Radiol. 2016;45:20150424

17-Salmi M, Tuomi J, Sirkkanen R, Ingman T, Mäkitie A. Rapid tooling method for soft customized removable oral appliances. Open Dent J. 2012;6:85

18-Salmi M, Paloheimo KS, Tuomi J, Wolff J, Mäkitie A. Accuracy of medical models made by additive manufacturing (rapid manufacturing). J Craniomaxillofac Surg. 2013;41:603-9

19-Salmi M, Paloheimo KS, Tuomi J, Ingman T, Mäkitie A. A digital process for additive manufacturing of occlusal splints: a clinical pilot study. J Royal Soc Interface. 2013;10:20130203

20-Chen H, Wang H, Lv P, Wang Y, Sun Y. Quantitative evaluation of tissue surface adaption of CAD-designed and 3D printed wax pattern of maxillary complete denture. BioMed Res Int. 2015;2015:1-5

21-Abduo J, Lyons K, Bennamoun M. Trends in computeraided manufacturing in prosthodontics: a review of the available streams. Int J Dent. 2014;2014:1-15

22-Aramany MA. Basic principles of obturator design for partially edentulous patients. Part I: classification. J prosthet dent. 1978;40:554-7

23-Yuan FS, Sun YC, Wang Y, Lü PJ. Accuracy evaluation of a new three-dimensional reproduction method of edentulous dental casts, and wax occlusion rims with jaw relation. Int J Oral Sci $2013 ; 5: 155-61$

24-Abdelhamid AM, Assaad N, Weheda AH. Evaluation of Mucosal Displacement and Denture Settlement for Direct Vs. Indirect Attachment Incorporation in Implant Assisted Mandibular Overdentures. J Dent Health Oral Disord Ther 2016;5:00146

25-Daly L, Bourke GJ. Interpretation and uses of medical statistics, 5th ed. John Wiley \& Sons; 2008.

26-Armitage P, Berry G, Matthews JN. Statistical methods in medical research, 4th ed. John Wiley \& Sons; 2008.

27-Goodacre BJ, Goodacre CJ, Baba NZ, Kattadiyil MT. Comparison of denture tooth movement between CADCAM and conventional fabrication techniques. J Prosthet Dent. 2018;119:108-15

28-Parvizi A, Lindquist T, Schneider R, Williamson D, Boyer D, Dawson DV. Comparison of the dimensional accuracy of injection-molded denture base materials to that of conventional pressure-pack acrylic resin. J Prosthodont. 2004;13:83-9

29-Baemmert RJ, Lang BR, Barco Jr MT, Billy EJ. The Effects of Denture Teeth on the Dimensional Accuracy of Acrylic Resin Denture Bases. Int J Prosthodont 1990;3:528-37

30-Ibrahim D, Broilo TL, Heitz C, de Oliveira MG, de Oliveira HW, Nobre SM, et al. Dimensional error of selective laser sintering, three-dimensional printing and PolyJet ${ }^{\mathrm{TM}}$ models in the reproduction of mandibular anatomy. $\mathrm{J}$ Craniomaxillofac Surg. 2009;37:167-73

31-El-Katatny I, Masood SH, Morsi YS. Error analysis of FDM fabricated medical replicas. Rapid Prototyp J. 2010;16:3643 